\title{
Cognitive Aspects of Survey Methodology
}

\author{
NORBERT SCHWARZ* \\ Institute for Social Research, University of Michigan, Ann Arbor, MI, USA
}

\begin{abstract}
SUMMARY
Since its initiation in the early 1980s, research into cognitive aspects of survey methods (CASM) has made considerable progress in illuminating the cognitive and communicative processes underlying survey responding. This article reviews key themes and developments, notes strengths and shortcomings and places the contributions to this special issue in this context. Copyright (C) 2007 John Wiley \& Sons, Ltd.
\end{abstract}

In the early 1980s, psychologists and survey methodologists deliberately attempted to create a new interdisciplinary field, which became known as CASM-Cognitive Aspects of Survey Methodology. The enterprise was jump-started by two conferences, one held in the United States in 1983 under the auspices of the National Research Council (Jabine, Straf, Tanur, \& Tourangeau, 1984) and one held in Germany in 1984, under the auspices of ZUMA (Hippler, Schwarz, \& Sudman, 1987). In the two decades since, work on cognitive aspects of survey measurement has developed at a rapid pace, resulting in a flurry of conferences, edited volumes and special issues of journals (Jobe \& Loftus, 1991; Lyberg et al., 1997; Presser et al., 2004; Schwarz, Park, Knäuper, \& Sudman, 1998; Schwarz \& Sudman, 1992, 1994, 1996; Sirken et al., 1999; Tanur, 1992) as well as three comprehensive monographs (Krosnick \& Fabrigar, in press; Tourangeau, Rips, \& Rasinski, 2000; Sudman, Bradburn, \& Schwarz, 1996). Moreover, major survey centres established cognitive laboratories to help with questionnaire development and courses in cognitive psychology have entered the curricula of graduate programs in survey methodology.

Drawing on psychological theories of language comprehension, memory and judgment, CASM researchers formulated models of the question answering process and tested them in laboratory experiments and experimental surveys. As the contributions to this special issue illustrate, work in this field has the potential to contribute to our understanding of basic psychological processes as well as to the improvement of survey methodology. This article summarises key themes of CASM research and places the contributions in this context.

\section{THE TASKS INVOLVED IN ANSWERING SURVEY QUESTIONS}

CASM researchers share wide agreement that answering a survey question poses several interrelated tasks (Cannell, Marquis, \& Laurent, 1977; Strack \& Martin, 1987; Tourangeau, 
1984). Respondents first need to interpret the question to understand what is meant and to determine which information they ought to provide. If the question is an attitude question, they may either retrieve a previously formed attitude judgment from memory, or they may form a judgment on the spot, based on whatever relevant information is accessible at that point in time. While survey researchers have typically hoped for the former, the latter is far more likely, consistent with current research into attitude construction in social psychology (Schwarz, in press; Smith \& Conrey, 2007). If the question is a behavioural question, respondents need to identify the behaviour of interest and recall relevant information. Survey researchers have typically hoped that respondents do so by reviewing the reference period specified in the question (such as 'last week' or 'last month') to identify relevant instances that can be 'counted'. Unless the behaviour is rare and important, such an enumeration strategy is rarely used; instead, respondents resort to a variety of estimation and inference strategies (Menon, 1994). Once a 'private' judgment is formed in respondents' minds, they have to communicate it to the researcher. To do so, they may need to format their judgment to fit the response alternatives provided as part of the question. Moreover, respondents may wish to edit their response before they communicate it, due to influences of social desirability and situational adequacy. Performance of each of these tasks is highly context dependent and often profoundly shaped by the research instrument. The resulting contextual influences are usually referred to as 'response effects' in the survey literature.

As Ongena and Dijkstra (2007, this issue) note, this widely shared conceptualisation of the components of the survey response process is exclusively respondent-focused, as is the bulk of CASM research. Yet the prototypical survey interview, conducted in person or on the phone, involves the collaboration of an interviewer and a respondent and is presumably as much affected by the interviewer's as by the respondent's performance. Historically, analyses of interviewer behaviour and its influence on survey data were a key feature of survey methods research (for a review see Cannell \& Kahn, 1968), with an emphasis on the interpersonal aspects of survey interviews. This approach lost much of its popularity when comprehensive meta-analyses of response effects, conducted in the early 1970s, indicated that the influence of task characteristics dwarfed the influence of interviewer and respondent characteristics (Sudman \& Bradburn, 1974). In response to this observation, survey methodologists turned increasingly to the investigation of the tasks presented by a survey question. This emphasis provided a natural point of contact for cognitive psychologists and dominates CASM research, as the contributions to this issue illustrate.

In parallel, qualitative studies in the traditions of ethnography and discourse analysis illuminated complications that arise in survey interviews (Gerber, 1999; Maynard, Houtkoop-Steenstra, Schaeffer, \& Van der Zouwen, 2002; Suchman \& Jordan, 1990), although many researchers found it difficult to derive general principles from the rich and compelling case studies presented. Ongena and Dijkstra (2007, this issue) connect these respondent-focused and interaction-focused research traditions and outline a model that links the tasks faced by interviewers and respondents. The emerging issues present a promising topic for experimental psychologists interested in collaborative cognition (Baltes \& Staudinger, 1996).

\section{MAKING SENSE OF QUESTIONS: COGNITION AND COMMUNICATION}

CASM's focus on task characteristics and respondent behaviour is apparent even where the research addresses the interplay of cognitive and communicative processes in question 
comprehension and judgment. Not surprisingly, survey researchers have always worried if respondents understand their questions as intended (for early discussions see Belson, 1968, 1981; Cantril, 1944; Payne, 1951). Accordingly, they devised numerous guidelines for good survey questions, emphasising the need to avoid complicated wordings and unfamiliar terms (Bradburn, Sudman, \& Warnsink, 2004). Although this advice is sound, it misses that question comprehension involves more than an understanding of the literal meaning of the utterance. When asked, 'What have you done today'? respondents will certainly understand the words - yet they may nevertheless not know on which behaviours they are to report. Should they report that they took a shower, for example or is the researcher not interested in this information? To provide a meaningful answer, respondents need to infer the questioner's intentions, that is the pragmatic meaning of the question. To do so, they rely on the tacit assumptions that govern the conduct of conversations in daily life (Grice, 1975) and draw on the context of the utterance to infer the intended meaning.

In surveys and laboratory experiments, the researcher's contributions to the conversation are not limited to explicit instructions and the questions asked. Instead, they include apparently 'formal' aspects of questionnaire design, from the choice of response alternatives to the formal characteristics of scales and the graphical lay-out of questionnaires. Numerous studies showed that respondents draw on such characteristics to infer the pragmatic meaning of questions in ways that can be conceptualised in terms of Grice's (1975) logic of conversation (for reviews see Clark \& Schober, 1992; Schwarz, 1996). Even the researcher's affiliation, gleaned from the letterhead, or the title of a survey can affect how respondents interpret the questions asked, as Galesic and Tourangeau (this volume) illustrate. In their study, respondents answered identical questions about work place behaviour presented as part of a 'Sexual Harassment Survey' conducted for Women Against Sexual Harassment or as part of a 'Work Atmosphere Survey' conducted for a Work Environment Institute. As expected, respondents perceived the same behaviours as more likely to represent sexual harassment when they were presented as part of a sexual harassment survey rather than a work atmosphere survey-after all, why else would they have been included? Moreover, once labelled as sexual harassment, they rated these behaviours as more bothersome and reported that they experienced them with a higher frequency. These findings highlight how contextual variables influence the pragmatic interpretation of questions, with downstream effects on frequency estimates. Processes of this type presumably underlie the observation that different surveys arrive at markedly different prevalence estimates, as Galesic and Tourangeau (2007, this issue) note in their review.

Deliberate reliance on contextual information is particularly likely when respondents have no opportunity to ask for clarification or to ground their understanding in an unconstrained exchange with the interviewer (Schober, 1999). This is the case under the self-administered conditions of mail and web surveys, where nobody is available to be asked, or when a well-trained interviewer responds, 'Whatever it means to you'. From a conversational perspective, such 'whatever-it-means-to-you' responses are nonsensical--after all, it is the questioner who has to decide what he or she wants to know. Nevertheless, they are a standard feature of interviewer training in survey research, where an assumed need for question standardisation trumps other concerns (Fowler \& Mangione, 1990). But as Suchman and Jordan (1990) noted, what needs to be standardised is question meaning, not question wording per se. This is particularly apparent when the question pertains to factual matters, where respondents' understanding of what, for example counts as 'furniture' may differ from the wisdom of the government agency that 
defined this category of household purchases. In an influential series of studies, Conrad and Schober (for a review see Schober \& Conrad, 2002) provided compelling evidence that a liberalisation of the standardisation requirement improves data quality under these conditions, although the same may not apply to attitude questions (see Sudman et al., 1996, for a discussion). In the present issue, they extend this work from personal interviews to web surveys and observe that respondents answer more accurately when they can request clarifications or when clarifications are automatically provided by the program if respondents take a long time to answer (Conrad, Schober, \& Coiner, 2007, this issue). These design features avoid burdening the questionnaire with numerous definitions for respondents who may not need them. The tricky question, of course, is how to determine when a respondent is likely to need clarifications. At present, we know little about how respondents decide that they do so, nor about how interviewers decide to offer clarifications when their instructions permit it (see Ongena \& Dijkstra, 2007, this issue). Metacognitive experiences of processing difficulty are likely to play an important role in respondents' decision, but have so far not received attention in CASM research. A systematic exploration of these issues will fill an important gap in the discussion of standardised interviewing.

To identify question comprehension problems at the pretesting stage, CASM researchers developed a rich arsenal of methods that are routinely applied in 'cognitive laboratories' at survey research centres and statistical agencies (for reviews see the contributions in Schwarz \& Sudman, 1996). Most widely used are cognitive interviews that combine elements of concurrent or retrospective think-aloud procedures with paraphrasing tasks (DeMaio \& Rothgeb, 1996), as well as detailed analyses of interviews conducted under field conditions (Fowler \& Cannell, 1996). From the perspective of survey practitioners, the development of improved pretesting procedures is often considered the most important and fruitful contribution of CASM research, although the contributions of this work to basic theorising have so far been limited.

\section{REPORTING ON ONE'S ATTITUDES: EVALUATIVE JUDGMENT IN CONTEXT}

Most psychologists and social scientists conceptualise attitudes as enduring dispositions that are 'expressed by evaluating a particular entity with some degree of favour or disfavour' (Eagly \& Chaiken, 1993, p. 1). From this perspective, contextual influences on respondents' attitude reports are a source of undesirable noise that clouds respondents' 'true' attitudes. An alternative approach treats attitudes as evaluative judgments that are formed on the spot, based on whatever information is accessible at that point in time (for variants of this approach see Lord \& Lepper, 1999; Schwarz, in press; Schwarz \& Bohner, 2001; Tourangeau, 1992). From this perspective, cognition stands in the service of action and only context-sensitive evaluation can guide behaviour in adaptive ways. Hence, any adaptive system of evaluation should be informed by past experience, but highly sensitive to the specifics of the present; it should overweigh recent experience at the expense of more distant experience, and experience from similar situations at the expense of experience from dissimilar situations; and it should take current goals and concerns into account to ensure that the assessment is relevant to what we attempt to do now (Schwarz, in press). Accordingly, contextual influences on attitude judgments are not an artifact but part and parcel of the phenomenon of interest. These diverging perspectives are the topic of current 
theoretical and methodological controversies in social psychology (see the contributions in Gawronski, in press); their development was, in part, stimulated by survey researchers' observation that attitude reports are highly context dependent (for reviews see Schuman \& Presser, 1981; Tourangeau \& Rasinski, 1988).

Since the early days of opinion polls (Cantril, 1944; Payne, 1951), survey researchers observed that minor variations in question wording, format and order can profoundly affect the obtained answers. By the early 1980s, they had amassed a solid body of reliably replicable findings, summarised in Schuman and Presser's (1981) influential Questions and Answers in Attitude Surveys, which set the stage for a collaboration with cognitive social psychologists, who had just turned to the information processing paradigm as a conceptual framework (Wyer \& Carlston, 1979). Two decades later, the underlying processes are increasingly well understood and conceptualised in comprehensive models that predict the emergence, direction and size of context effects in attitude reports, as well as their generalisation across related items (Schwarz \& Bless, 1992, in press; Sudman et al., 1996; Tourangeau, 1999).

In the present issue, Chessa and Holleman apply cognitive modelling to one of the classic question wording effects in the survey literature, using a methodology that is under-represented in CASM research. Five decades ago, Rugg (1941) observed that Americans were more likely to support freedom of speech when the question asked whether speeches against democracy should be 'forbidden' (yes/no) than when it asked whether they should be 'allowed' (yes/no). This frequently replicated finding became known as the 'forbid-allow asymmetry' and most authors focused on a comparison of 'forbidding' vs. 'not allowing'. However, the overall pattern extends beyond this contrast and respondents are more likely to answer 'No' to either question form. Later research showed that this response pattern is driven by indifferent respondents (Hippler \& Schwarz, 1986). Those who strongly favour the issue respond consistently to both question forms, answering 'Yes' to the allow version and 'No' to the forbid version; conversely, those who strongly oppose the issue answer 'Yes' to the forbid version and 'No' to the allow version. No asymmetry is observed for these respondents. Indifferent respondents, however, answer 'No' to either question because they neither want to encourage the behaviour by allowing it, nor to discourage the behaviour by forbidding it; if given a choice, they would prefer a 'do not-do-anything-about-it' response. As a result, both question forms receive more 'No' than 'Yes' responses: In the 'allow' version, the 'No' category includes those opposed to the issue plus indifferent respondents; in the 'forbid' version it includes those in favour of the issue plus indifferent respondents. Accordingly, the percentage of indifferent respondents determines the size of the forbid-allow asymmetry for a given topic, often resulting in large differences in the effects obtained across items (as illustrated in Chessa and Holleman's Table 1). Chessa and Holleman's (2007, this issue) analysis of response latencies suggests that the asymmetry emerges at the response stage, when respondents need to map their opinion onto the restricted 'Yes' or 'No' options. Theoretically, this should be particularly difficult for indifferent respondents, whose position does not easily fit these response alternatives (Hippler \& Schwarz, 1986). Unfortunately, the available data preclude an analysis of this possibility because respondents' attitude position has not been assessed. Future research may fruitfully explore whether the observed differences in response time at the question answering stage hold for all respondents, as Chessa and Holleman's focus on the connotations of the terms 'forbid' and 'allow' suggests, or whether they are driven by indifferent respondents, who face difficulties at the response formatting stage. 


\section{REPORTING ON ONE'S BEHAVIOUR: MEMORY AND ESTIMATION}

Much of what we know about human behaviour and the state of society-from dietary habits to the utilisation of health care services, the dynamics of poverty and the nation's unemployment rate-is based on self-reports collected in representative sample surveys. The accuracy of these reports has long been a topic of concern (for an early example see Cannell, Fisher, \& Bakker, 1965) and even major life-events, like overnight hospitalisations (Cannell et al., 1965) or spells of unemployment (Mathiowetz \& Duncan, 1988) are frequently under-reported. Hence, numerous record check studies identified a 'great deal of error', as Wentland and Smith (1993, p. 99) concluded in a comprehensive review. Historically, survey researchers' attempts to identify sources and patterns of error have been hampered by a lack of comprehensive process models and overly simplistic assumptions about memory. CASM research had a profound impact in this domain and survey data collection is increasingly informed by current theorising about autobiographical memory, which highlights how the hierarchically nested structure of autobiographical memory can facilitate or impair recall (for reviews see Belli, 1998; Shum \& Rips, 1999).

Drawing on these models, Belli (1998) developed a method designed by demographers to assess respondents' life histories (Freedman, Thornton, Camburn, Alwin, \& YoungDeMarco, 1988) into a general procedure for collecting autobiographical information, dubbed the Event History Calendar. By crossing the behaviours of interest with a time-line, the method presents a complex grid that allows respondents to place various behaviours and events in time and space, taking advantage of the observation that recalling information in one domain may bring to mind temporally or thematically related information in other domains. In this issue, van der Vaart and Glasner's (2007, this issue) use of timelines in telephone surveys illustrates this approach.

Considerable progress has also been made in the assessment of behavioural frequency reports. Survey researchers have long assumed that most frequency reports are based on a recall-and-count strategy and that errors are either due to forgetting or to the misdating of events. These assumptions were challenged by the observation that respondents frequently rely on estimation strategies (e.g. Blair \& Burton, 1987), making systematic use of features of the questionnaire, like the numeric values of frequency scales, to arrive at a plausible estimate (e.g. Schwarz, Hippler, Deutsch, \& Strack, 1985). As a result, frequency reports are highly context dependent, often shaped by the research instrument. Later research (e.g., Brown, 2002; Menon, 1994) integrated these observations in multi-strategy models of frequency estimation and identified the conditions that give rise to different strategies. Brown's (2002) multiple-strategy approach assumes that strategy selection is a function of the format in which relevant information is represented in memory, which in turn depends on characteristics of the respective behaviour. Brown and colleagues (2007, this issue) illustrate this approach with an analysis of the mnemonic consequences of activities and emotions and their impact on retrieval strategies. The observed accuracy of emotion reports is impressive, although other findings (for a review see Robinson \& Clore, 2002) suggest that it is partly a function of the coarse reporting level used, which is limited to whether the respondent experienced the emotion at all during a given day. Brown and colleagues' (2007, this issue) coarse reporting level also attenuates a frequently overlooked problem that can thwart comparisons pertaining to reference periods of differential length (like a day vs. a week in their study). When respondents are asked, for example how often they have been angry, they need to determine if the researcher's interest includes minor irritations or only episodes of major anger. When the question pertains to 'today', they infer 
that minor irritations are part of what they are to report on, given that major annoyances are unlikely to occur on a daily basis. When asked how often they have been angry 'last week', however, they infer that the researcher is interested in more serious instances of anger-after all, they can hardly be expected to remember all the minor irritations of the week. This shift in the inferred pragmatic meaning of the question results in higher frequency reports for short than for long reference periods, reflecting the differential actual frequency of minor versus major episodes of anger (Winkielman, Knäuper, \& Schwarz, 1998). Accordingly, mismatches between reports pertaining to reference periods of differential length are not exclusively due to memory processes and it is often difficult to disentangle the effects of question interpretation and forgetting.

When behavioural reports are conceptualised in the overall framework of the question answering process, it becomes apparent that memory processes are only one of the determinants of their accuracy. As already noted, respondents may report on a behaviour that does not match what the researcher had in mind (e.g. Schober \& Conrad, 2002) and contextual variables may influence question interpretation with downstream effects on frequency reports (Galesic \& Tourangeau, 2007, this issue; Winkielman et al., 1998). Moreover, respondents may hesitate to report that they do engage in undesirable behaviours or fail to engage in desirable ones. The extent to which such socially desirable responding (for a review see DeMaio, 1984) reflects deliberate misreporting or a self-serving reconstruction of what one 'must have' done is the topic of some controversy and it is often difficult to determine whether respondents lie, manage to see themselves in a positive light or merely rely on cultural norms and generic self-knowledge in reconstructing their past behaviour (Dunning, 2001; Kunda, 1999; Ross, 1989). Stocké and Stark's (2007, this issue) analysis of reported voting behaviour bears on this ambiguity. Consistent with previous studies, they observe that respondents over-report voting behaviour and the more so, the more time has elapsed since election day. More important, the influence of temporal distance is more pronounced for respondents with high political involvement. Stocké and Stark suggest that these respondents hold stronger political participation norms and hence are subject to stronger social desirability bias. This bias is assumed to exert its strongest influence under conditions of poor memory for one's actual behaviour, consistent with the observation that self-serving reconstructions are most likely under conditions of ambiguity (Kunda, 1999). If respondents solely cared about their self-presentation in the interview, they would presumably also over-report when they are aware of their absence from the ballot box. While motivational interpretations of such findings are plausible, it is difficult to rule out a purely cognitive account. Being unable to recall with any certainty whether they voted in the last election or not, respondents may draw on their usual behaviour to infer what they 'must have' done (Ross, 1989. Those with higher political involvement presumably participate in elections more regularly and hence are also more likely to infer that they must have done so in the last election.

\section{A TWO-WAY BRIDGE?}

The initiators of the first CASM conferences hoped to build a two-way bridge between cognitive psychology and survey methods to facilitate an exchange that would advance basic research and improve survey practice. In the two decades since these conferences, this bridge has seen considerable traffic. However, much of this traffic has been from psychology to survey methods. This is not surprising. Survey research offers a method, not a substantive body of theorising about human cognition and behaviour. Hence, the contact 
with survey researchers influenced cognitive theorising mostly by exposing psychologists to new tasks and phenomena, like context effects in attitude measurement and systematic error patterns in reports of everyday behaviours, not by contributing novel theoretical perspectives. One might have hoped, however, that the large amount of questionnaire pretesting done in the cognitive laboratories of major survey research centres and statistical agencies would contribute to a cumulative body of knowledge about principles of questionnaire design. To date, this has not been the case. As O'Muircheartaigh (1999), p. 51) noted, 'The function of the cognitive laboratory (...) is not primarily the development of principles of question or questionnaire design. Rather, it is to provide a facility for pretesting questionnaires for use in ongoing surveys. It is evaluated not by its contributions to general principles or knowledge, but by its throughput of questionnaires in a documented and timely manner'. Unfortunately, this produces considerable redundancy and many missed opportunities for general insights.

Nevertheless, survey research provides many opportunities for broadening the agenda of cognitive research beyond the analysis of respondents' and interviewers' tasks. To date, cognitive psychologists have rarely taken advantage of the unique opportunities that representative sample surveys afford. Working within the paradigm of general information processing models, they have mostly focused on 'inside-the-head' phenomena, trusting that any mind works pretty much like any other mind--an assumption that makes the use of representative samples an unnecessary luxury, in particular, when this luxury comes at the cost of limited experimental control. But much as psychology's shift from behaviourism to information processing has made psychologists interesting partners for survey methodological work, psychologists' growing interest in the socially and culturally situated nature of cognition may eventually make survey researchers interesting partners for basic psychological work. For example representative samples provide a prime avenue for studying the influence of social location on people's construction of the world in which they live (e.g. Hardin \& Higgins, 1996), for exploring how historical contexts shape autobiographical memory and the reconstruction of history (e.g. Schuman, Rieger, \& Gaidys, 1994) or for assessing how beliefs spread in a population (e.g. Nowack, Szamrej, \& Latane, 1990). Moreover, cross-national surveys provide promising opportunities for testing theories of cultural differences in cognition, communication and autobiographical memory, issues that bear on basic psychological theorising as well as the culture-sensitivity of context effects in surveys (e.g. Schwarz, 2003). Hopefully, future decades will see more two-way traffic on CASM's bridge.

\section{REFERENCES}

Baltes, P. B., \& Staudinger, U. M. (Eds.). (1996). Interactive minds. New York: Cambridge University Press.

Belson, W. A. (1968). Respondent understanding of survey questions. Polls, 3, 1-13.

Belson, W. A. (1981). The design and understanding of survey questions. Aldershot: Gower.

Belli, R. (1998). The structure of autobiographical memory and the event history calendar: Potential improvements in the quality of retrospective reports in surveys. Memory, 6, 383-406.

Blair, E., \& Burton, S. (1987). Cognitive processes used by survey respondents to answer behavioral frequency questions. Journal of Consumer Research, 14, 280-288.

Bradburn, N., Sudman, S., \& Wansink, B. (2004). Asking questions (2nd ed.). San Francisco: Jossey Bass.

Brown, N. R. (2002). Encoding, representing, and estimating event frequencies: Multiple strategy perspective. In P. Sedlmeier, \& T. Betsch (Eds.), Etc.: Frequency processing and cognition (pp. 37-54). New York: Oxford University Press. 
Brown, N. R., Williams, R. L., Barker, E. T., \& Galambos, N. L. (2007). Estimating frequencies of emotions and actions: A web-based diary study. Applied Cognitive Psychology, 21, 259-276 (this issue). DOI: 10.1002/acp.1303

Cannell, C. F., Fisher, G., \& Bakker, T. (1965). Reporting on hospitalization in the Health Interview Survey. Vital and Health Statistics (PHS Publication No. 1000, Series 2, No. 6). Washington, D.C.: US Government Printing Office.

Cannell, C. F., \& Kahn, R. L. (1968). Interviewing. In G. Lindzey, \& E. Aronson (Eds.), The handbook of social psychology (Vol. 2). Reading, MA: Addison-Wesley.

Cannell, C. F., Marquis, K. H., \& Laurent, A. (1977). A summary of studies of interviewing methodology. Vital and Health Statistics, Series 2, No. 69 (DHEW Publication No. HRA 77-1343). Washington, DC: Government Printing Office.

Cantril, H. (1944). Gauging public opinion. Princeton, N.J.: Princeton University Press.

Chessa, A. G., \& Holleman, B. C. (2007). Answering attitudinal questions: Modelling the response process underlying contrastive questions. Applied Cognitive Psychology, 21, 203-225 (this issue). DOI: $10.1002 /$ acp. 1337

Clark, H. H., \& Schober, M. F. (1992). Asking questions and influencing answers. In J. M. Tanur (Ed.), Questions about questions (pp. 15-48). New York: Russel Sage.

Conrad, F. G., Schober, M. F., \& Coiner, T. (2007). Bringing features of human dialogue to web surveys. Applied Cognitive Psychology, 21, 165-187 (this issue). DOI: 10.1002/acp.1335

DeMaio, T. J. (1984). Social desirability and survey measurement: A review. In C. F. Turner, \& E. Martin (Eds.), Surveying subjective phenomena (Vol. 2, pp. 257-281). New York: Russell Sage.

DeMaio, T. J., \& Rothgeb, J. M. (1996). Cognitive interviewing techniques: In the lab and in the field. In N. Schwarz, \& S. Sudman (Eds.), Answering questions: Methodology for determining cognitive and communicative processes in survey research (pp. 177-196). San Francisco: Jossey-Bass.

Dunning, D. (2001). On the motives underlying social cognition. In A. Tesser, \& N. Schwarz (Eds.), Blackwell handbook of social psychology: Intraindividual processes (pp. 348-374). Oxford, UK: Blackwell.

Eagly, A. H., \& Chaiken, S. (1993). The psychology of attitudes. Fort Worth, TX: Harcourt Brace Jovanovich College.

Fowler, F. J., \& Cannell, C. F. (1996). Using behavioral coding to identify cognitive problems with survey questions. In N. Schwarz, \& S. Sudman (Eds.), Answering questions: Methodology for determining cognitive and communicative processes in survey research (pp. 15-36). San Francisco: Jossey-Bass.

Fowler, F. J., \& Mangione, T. W. (1990). Standardized survey interviewing: Minimizing interviewer related error. Newbury Park, CA: Sage.

Freedman, D., Thornton, A., Camburn, D., Alwin, D., \& Young-DeMarco, L. (1988). The life history calendar: A technique for collecting retrospective data. Sociological Methodology, 18, 37-68.

Galesic, M., \& Tourangeau, R. (2007). What is sexual harassment? It depends on who asks! Framing effects on survey responses. Applied Cognitive Psychology, 21, 189-202 (this issue). DOI: 10.1002/acp.1336

Gawronski, B. (Ed.). (in press). What is an attitude? Special issue of Social Cognition.

Gerber, E. R. (1999). The view from anthropology: Ethnography and the cognitive interview. In M. Sirken, D. Hermann, S. Schechter, N. Schwarz, J. Tanur, \& R. Tourangeau (Eds.), Cognition and survey research (pp. 217-234). New York: Wiley.

Grice, H. P. (1975). Logic and conversation. In P. Cole, \& J. L. Morgan (Eds.), Syntax and semantics: Speech acts (Vol. 3, pp. 41-58). New York: Academic Press.

Hardin, C. D., \& Higgins, E. T. (1996). Shared reality: How social verification makes the subjective objective. In R. M. Sorrentino, \& E. T. Higgins (Eds.), Handbook of motivation and cognition: The interpersonal context (Vol. 3, pp. 28-84). New York: Guilford.

Hippler, H. J., \& Schwarz, N. (1986). Not forbidding isn't allowing: The cognitive basis of the forbid-allow asymmetry. Public Opinion Quarterly, 50, 87-96.

Hippler, H. J., Schwarz, N., \& Sudman, S. (Eds.). (1987). Social information processing and survey methodology. New York: Springer Verlag.

Jabine, T. B., Straf, M. L., Tanur, J. M., \& Tourangeau, R. (Eds.). (1984). Cognitive aspects of survey methodology: Building a bridge between disciplines. Washington, DC: National Academy Press.

Jobe, J., \& Loftus, E. (Eds.). (1991). Cognitive aspects of survey methodology. Special issue of Applied Cognitive Psychology, 5, 173-296. 
Krosnick, J. A., \& Fabrigar, L. R. (in press). The handbook of questionnaire design. New York, NY: Oxford University Press.

Kunda, Z. (1999). Social cognition. Cambridge, MA: MIT Press.

Lord, C. G., \& Lepper, M. R. (1999). Attitude representation theory. Advances in Experimental Social Psychology, 31, 265-343.

Lyberg, L., Biemer, P., Collins, M., DeLeeuw, E., Dippo, C., Schwarz, N., \& Trewin, D. (Eds.). (1997). Survey measurement and process quality. Chichester, UK: Wiley.

Mathiowetz, N. A., \& Duncan, G. J. (1988). Out of work, out of mind: Response errors in retrospective reports of unemployment. Journal of Business and Economic Statistics, 6, 221-229.

Maynard, D., Houtkoop-Steenstra, H., Schaeffer, N. C., \& van der Zouwen, J. (Eds.). (2002). Standardization and tacit knowledge: Interaction and practice in the survey interview. New York: John Wiley \& Sons.

Menon, G. (1994). Judgments of behavioral frequencies: Memory search and retrieval strategies. In N. Schwarz, \& S. S. Sudman (Eds.), Autobiographical memory and the validity of retrospective reports (pp. 161-172). New York: Springer Verlag.

Nowack, A., Szamrej, J., \& Latane, B. (1990). From private attitude to public opinion: A dynamic theory of social impact. Psychological Review, 97, 362-376.

O’Muircheartaigh, C. O. (1999). CASM: Success, failure, and potential. In M. Sirken, D. Hermann, S. Schechter, N. Schwarz, J. Tanur, \& R. Tourangeau (Eds.), Cognition and survey research (pp. 39-63). New York: Wiley.

Ongena, Y. P., \& Dijkstra, W. (2007). A model of cognitive processes and conversational principles in survey interview interaction. Applied Cognitive Psychology, 21, 145-163 (this issue). DOI: 10.1002/acp.1334

Payne, S. L. (1951). The art of asking questions. Princeton: Princeton University Press.

Presser, S., Rothgeb, J. M., Couper, M. P., Lessler, J. T., Martin, E., Martin, J., \& Singer, E. (Eds.). (2004). Methods for testing and evaluating survey questionnaires. New York: Wiley.

Robinson, M. D., \& Clore, G. L. (2002). Belief and feeling: Evidence for an accessibility model of emotional self-report. Psychological Bulletin, 128, 934-960.

Ross, M. (1989). The relation of implicit theories to the construction of personal histories. Psychological Review, 96, 341-357.

Rugg, D. (1941). Experiments in wording questions. Public Opinion Quarterly, 5, 91-92.

Schober, M. F. (1999). Making sense of questions: An interactional approach. In M. Sirken, D. Hermann, S. Schechter, N. Schwarz, J. Tanur, \& R. Tourangeau (Eds.), Cognition and survey research (pp. 77-94). New York: Wiley.

Schober, M. F., \& Conrad, F. G. (2002). A collaborative view of standardized survey interviews. In D. Maynard, H. Houtkoop-Steenstra, N. C. Schaeffer, \& J. van der Zouwen (Eds.), Standardization and tacit knowledge: Interaction and practice in the survey interview (pp. 67-94). New York: John Wiley \& Sons.

Schuman, H., \& Presser, S. (1981). Questions and answers in attitude surveys. New York: Academic Press.

Schuman, H., Rieger, C., \& Gaidys, V. (1994). Collective memories in the United States and Lithuania. In N. Schwarz, \& S. Sudman (Eds.), Autobiographical memory and the validity of retrospective reports (pp. 313-334). New York: Springer Verlag.

Schwarz, N. (1996). Cognition and communication: Judgmental biases, research methods and the logic of conversation. Hillsdale, NJ: Erlbaum.

Schwarz, N. (2003). Culture-sensitive context effects: A challenge for cross-cultural surveys. In J. Harkness, F. van de Vijver, \& P. Ph. Mohler (Eds.), Cross-cultural survey methods (pp. 93-100). New York: Wiley.

Schwarz, N. (in press). Attitude construction: Evaluation in context. Social Cognition.

Schwarz, N., \& Bless, H. (1992). Constructing reality and its alternatives: Assimilation and contrast effects in social judgment. In L. L. Martin, \& A. Tesser (Eds.), The construction of social judgment (pp. 217-245). Hillsdale, NJ: Erlbaum.

Schwarz, N., \& Bless, H. (in press). Mental construal processes: The inclusion/exclusion model. In D. A. Stapel, \& J. Suls (Eds.), Assimilation and contrast in social psychology. Philadelphia, PA: Psychology Press.

Schwarz, N., \& Bohner, G. (2001). The construction of attitudes. In A. Tesser, \& N. Schwarz (Eds.), Blackwell handbook of social psychology: Intraindividual processes (pp. 436-457). Oxford, UK: Blackwell Publishers. 
Schwarz, N., Hippler, H. J., Deutsch, B., \& Strack, F. (1985). Response scales: Effects of category range on reported behavior and subsequent judgments. Public Opinion Quarterly, 49, 388-395.

Schwarz, N., Park, D., Knäuper, B., \& Sudman, S. (Eds.). (1999). Cognition, aging, and self-reports. Philadelphia, PA: Psychology Press.

Schwarz, N., \& Sudman, S. (Eds.). (1992). Context effects in social and psychological research. New York: Springer Verlag.

Schwarz, N., \& Sudman, S. (1994). Autobiographical memory and the validity of retrospective reports. New York: Springer Verlag.

Schwarz, N., \& Sudman, S. (Eds.). (1996). Answering questions: Methodology for determining cognitive and communicative processes in survey research. San Francisco: Jossey-Bass.

Shum, M. S., \& Rips, L. J. (1999). The respondent's confession: Autobiographical memory in the context of surveys. In Sirken, M., Hermann, D., Schechter, S., Schwarz, N., Tanur, J., \& Tourangeau, R. (Eds.), Cognition and survey research (pp. 95-109). New York: Wiley.

Sirken, M., Hermann, D., Schechter, S., Schwarz, N., Tanur, J., \& Tourangeau, R. (Eds.). (1999). Cognition and survey research. New York: Wiley.

Smith, E. R., \& Conrey, F. R. (2007). Mental representations are states not things: Implications for implicit and explicit measurement. In B. Wittenbrink, \& N. Schwarz (Eds.), Implicit measures of attitudes: Progress and controversies. (pp. 247-264). New York: Guilford.

Stocké, V., \& Stark, T. (2007). Political involvement and memory failure as interdependent determinants of vote overreporting. Applied Cognitive Psychology, 21, 239-257 (this issue). DOI: 10.1002/acp.1339

Strack, F., \& Martin, L. (1987). Thinking, judging, and communicating: A process account of context effects in attitude surveys. In H. J. Hippler, N. Schwarz, \& S. Sudman (Eds.), Social information processing and survey methodology (pp. 123-148). New York: Springer Verlag.

Suchman, L., \& Jordan, B. (1990). Interactional troubles in face-to-face interviews. Journal of the American Statistical Association, 85, 232-241.

Sudman, S., \& Bradburn, N. M. (1974). Response effects in surveys: A review and synthesis. Chicago: Aldine, 1974.

Sudman, S., Bradburn, N., \& Schwarz, N. (1996). Thinking about answers: The Application of cognitive processes to survey methodology. San Francisco, CA: Jossey-Bass.

Tanur, J. M. (Ed.). (1992). Questions about questions. New York: Russel Sage.

Tourangeau, R. (1984). Cognitive science and survey methods: A cognitive perspective. In T. Jabine, M. Straf, J. Tanur, \& R. Tourangeau (Eds.), Cognitive aspects of survey methodology: Building a bridge between disciplines (pp. 73-100). Washington, DC: National Academy Press.

Tourangeau, R. (1992). Attitudes as memory structures: Belief sampling and context effects. In N. Schwarz, \& S. Sudman (Eds.), Context effects in social and psychological research (pp. 35-47). New York: Springer Verlag.

Tourangeau, R. (1999). Context effects on answers in attitude questions. In M. Sirken, D. Hermann, S. Schechter, N. Schwarz, J. Tanur, \& R. Tourangeau (Eds.), Cognition and survey research (pp. 111-132). New York: Wiley.

Tourangeau, R., \& Rasinski, K. A. (1988). Cognitive processes underlying context effects in attitude measurement. Psychological Bulletin, 103, 299-314.

Tourangeau, R., Rips, L. J., \& Rasinski, K. (2000). The psychology of survey response. Cambridge: Cambridge University Press.

van der Vaart, W., \& Glasner, T. (2007). Applying a timeline as a recall aid in a telephone survey: A record check study. Applied Cognitive Psychology, 21, 227-238 (this issue). DOI: 10.1002/ acp. 1338

Wentland, E. J., \& Smith, K. W. (1993). Survey responses: An evaluation of their validity. San Diego, CA: Academic Press.

Winkielman, P., Knäuper, B., \& Schwarz, N. (1998). Looking back at anger: Reference periods change the interpretation of (emotion) frequency questions. Journal of Personality and Social Psychology, 753, 719-728.

Wyer, R. S., \& Carlston, D. E. (1979). Social cognition, inference, and attribution. Hillsdale, NJ: Erlbaum. 